\title{
REGIONAL GROSS DOMESTIC PRODUCT OF GEORGIA. METHODOLOGICAL CHANGES
}

\author{
Associate Professor, Inga Benashvili, Georgia, Tbilisi, Teaching University Geomedi, Geostat \\ Lecturer, Mamuka Benashvili, Georgia, Tbilisi, Teaching University Geomedi, Geostat
}

DOI: https://doi.org/10.31435/rsglobal_ws/30112019/6779

\section{ARTICLE INFO}

Received: 25 September 2019

Accepted: 20 November 2019

Published: 30 November 2019

\section{KEYWORDS}

Regional Gross Domestic Product, Regional Gross Value Added, Output,

Intermediate consumption. \begin{abstract}
The paper is devoted to the methodological changes in the calculation of regional Gross Domestic Product (GDP), mainly due to the introduction of the 2008 version of the System of National Accounts in Georgia. Other changes are related to the transition to a new classification system of economic activity (NACE rev2). Because of this, the regional structure of GDP has changed significantly.

Regional GDP on a per capita basis, in 2018 Tbilisi ranks first (6122,5 USD). Then it will be followed by Adjara (5514.3 USD). Their rate is significantly higher than the national rate (4722.0 USD).

The priority directions for calculating regional GDP in Georgia are as follows: - Receiving data directly from local units (local KAUs) by improving information sources;

-More detailing of regionalization. In particular, at the municipal level;

- Calculate regional GDP at constant prices.
\end{abstract}

Citation: Inga Benashvili, Mamuka Benashvili. (2019) Regional Gross Domestic Product of Georgia. Methodological Changes. World Science. 11(51), Vol.3. doi: 10.31435/rsglobal_ws/30112019/6779

Copyright: (C) 2019 Inga Benashvili, Mamuka Benashvili. This is an open-access article distributed under the terms of the Creative Commons Attribution License (CC BY). The use, distribution or reproduction in other forums is permitted, provided the original author(s) or licensor are credited and that the original publication in this journal is cited, in accordance with accepted academic practice. No use, distribution or reproduction is permitted which does not comply with these terms.

Introduction. Regional statistics, including regional GDP, play an important role in the development and implementation of regional policy.

Regional Gross Domestic Product (regional GDP) is the gross value expressed in the market prices of final goods and services produced in a region's economy over a period of time.

Regional GDP information is available in Georgia from December 25, 2018. Until that time, only the region's value added was calculated. There was no disruption of taxes and subsidies in the regional context.

The conceptual basis for calculating regional GDP is the methodological guidance of SNA 2008, ESA 2010 and Eurostat 2013 Regional Accounts Manual.

Paragraphs 18.45-18.54 of SNA 2008 and points 13.01-13.55 of ESA 2010 refer to regional accounts.

There are three internationally recognized methods of regionalization for calculating regional GDP:

1. Bottom-up method;

2. Top-down methods;

3. Mixed methods.

Bottom-up method involves collecting data directly from local KAUs or households and then aggregating them.

The pseudo-bottom-up method is used when we do not have data directly from local KAUs or households. Evaluation of data on local units comes from enterprises.

Bottom-up method involves collecting data directly from local KAUs or households and then aggregating them.

Top-down methods imply the existence of data at a higher level than the local unit (eg country level) and subsequently distribute this data to regions in proportion to the (related) indicators close to this indicator. For example, wages may be proportional to the regional distribution of employment.

Mixed methods imply mixed use of ascending and descending methods. 
The choice of method depends on statistical information sources.

There mainly used a top down method in the case of Georgia. The regional value added is estimated in proportion to the turnover, output, value added, as well as regional distribution of employment.

Taxes and subsidies are distributed by region in proportion to the current regional distribution of value added.

The calculation of regional GDP is based on the administrative-territorial arrangement of the country. Indicators are limited to regions only; Information is not available at the municipal level. The calculations till now were based on SNA 1993. The paper is attempt to move to SNA 2008.

The regional GDP calculation methodology is similar to the country's GDP calculation methodology. From the production, expenditure and revenue methods in Georgia only the production method is used, according to which regional GDP = total value added by economic activities + net taxes (taxes - subsidies) on production and imports. Value added is taken as the difference between total output and intermediate consumption.

Research results. These are first attempt for calculating regional GDP due to the turn to SNA 2008 and to other changes. These are preliminary estimates that are subject to further clarification. The top down method was used in almost all branches of economy except agriculture. There is information on each type of product in agriculture at the regional level, both in the crop production and in the livestock sector. Other activities were mainly distributed in proportion to the regional distribution of employment. Also in proportion to business output.

The table below shows the results of calculation of Regional GDP of Georgia in 2017 and 2018.

Table 1. Regional GDP of Georgia in 2017-2018, at current prices, mln. GEL

\begin{tabular}{|l|r|r|}
\hline & \multicolumn{1}{|c|}{$\mathbf{2 0 1 7}$} & \multicolumn{1}{c|}{$\mathbf{2 0 1 8}$} \\
\hline Tbilisi & $14,642.6$ & $18,076.3$ \\
Adjara AR & $4,919.2$ & $4,859.4$ \\
Guria & 875.0 & 890.0 \\
Imereti & $5,869.2$ & $5,692.1$ \\
Racha-Lechkhumi and Kvemo Svaneti & 356.5 & 356.9 \\
Kakheti & $2,645.2$ & $3,086.1$ \\
Mtskheta-Mtianeti & 876.9 & $1,045.7$ \\
Samegrelo-Zemo Svaneti & $3,015.6$ & $2,707.9$ \\
Samtskhe-Javakheti & $1,267.7$ & $1,375.8$ \\
Kvemo Kartli & $4,105.6$ & $4,066.5$ \\
Shida Kartli & $2,188.2$ & $2,442.7$ \\
\hline Gross Domestic Product at market pricies & $\mathbf{4 0 , 7 6 1 . 7}$ & $\mathbf{4 4 , 5 9 9 . 3}$ \\
\hline
\end{tabular}

According to 2018 data, the regional structure of GDP is as follows: Tbilisi - $40.5 \%$, Imereti -

12.8\%, Adjara - 10.9\%, Kvemo Kartli (9.1\%), Kakheti - 6.9\%, Samegrelo-Zemo Svaneti (6.1 percent).

The smallest share $-0.8 \%$ comes from Racha-Lechkhumi and Kvemo Svaneti.

Important information is also included in the per capita regional GDP calculation presented in the table below.

Table 2. Gross Domestic Product of Georgia per capita by regions at current pricies, USD

\begin{tabular}{|l|c|c|}
\hline & $\mathbf{2 0 1 7}$ & $\mathbf{2 0 1 8}$ \\
\hline Tbilisi & $5,066.4$ & $6,122.5$ \\
Adjara AR & $5,689.0$ & $5,514.3$ \\
Guria & $3,142.4$ & $3,193.3$ \\
Imereti & $4,581.0$ & $4,471.8$ \\
Racha-Lechkhumi and Kvemo Svaneti & $4,655.5$ & $4,697.4$ \\
Kakheti & $3,344.4$ & $3,883.1$ \\
Mtskheta-Mtianeti & $3,722.7$ & $4,400.3$ \\
Samegrelo-Zemo Svaneti & $3,727.6$ & $3,354.4$ \\
Samtskhe-Javakheti & $3,228.3$ & $3,501.7$ \\
Kvemo Kartli & $3,797.5$ & $3,707.8$ \\
Shida Kartli & $3,356.8$ & $3,731.6$ \\
\hline Gross Domestic Product per capita & $\mathbf{4 , 3 5 8 . 5}$ & $\mathbf{4 , 7 2 2 . 0}$ \\
\hline
\end{tabular}

On a per capita basis, Tbilisi ranks first. Then it will be followed by Adjara. Their rate is significantly higher than the national rate. 
The sectoral structure of GDP in the region is important. Specifically which activities make up the largest share. The fields are based on the National Classification of Economic Activities of Georgia (NACE Rev.2) at the level of section.

The chart below illustrates the sectoral structure of regional GDP.

Chart 1. Structure of Gross Regional Value Added by types of economic activities, 2018, Percent

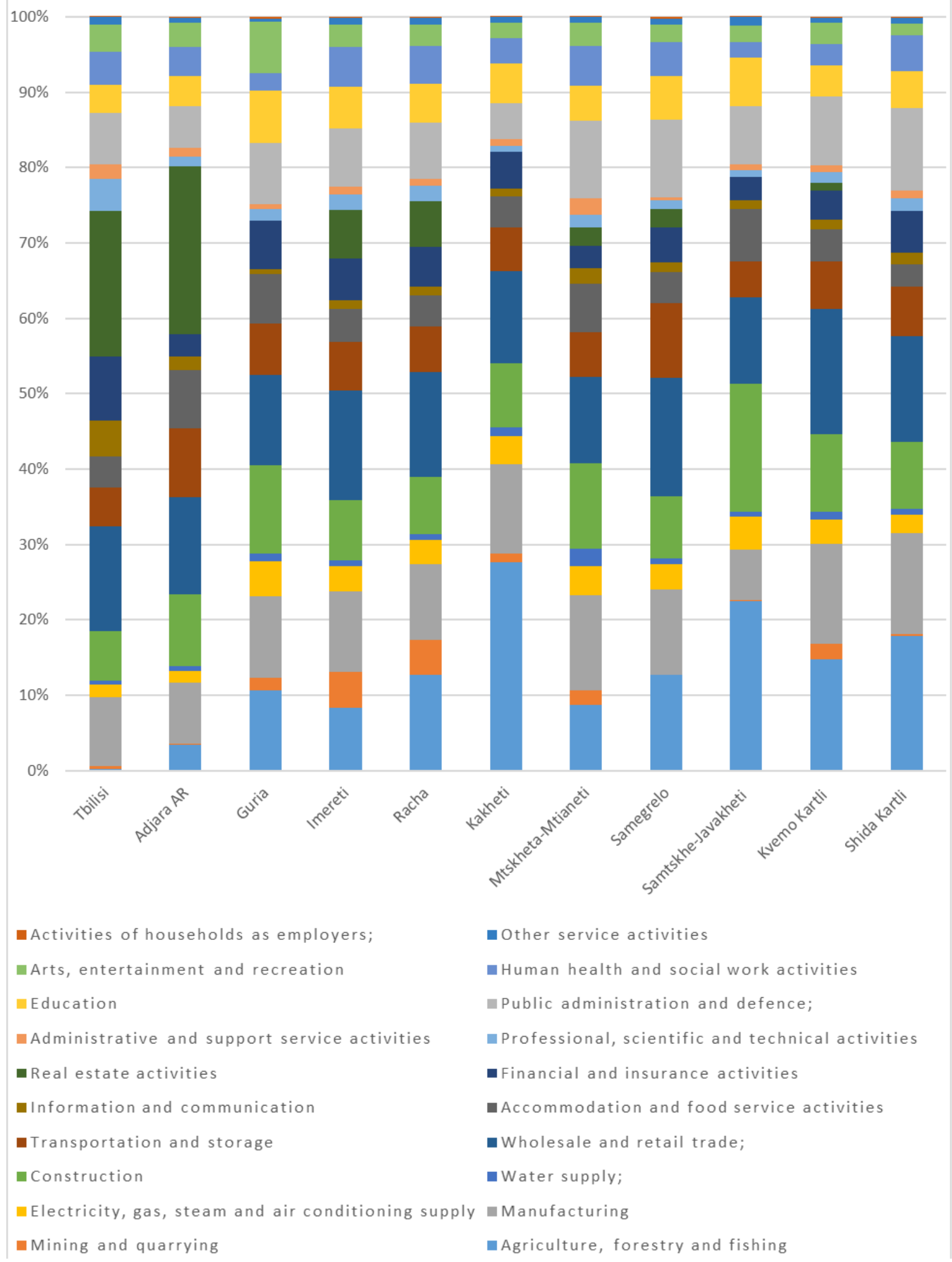

Fig.1. 
The largest component of the regional GDP - Tbilisi's highest sectoral share in 2017 and 2018 comes from real estate activities, trade, manufacturing, Financial and insurance activities, Public administration and defence, construction, transportation and storage; The main sectors of Imereti are: trade, manufacturing, agriculture, construction, public administration, real estate; Adjara Region - Real estate, trade, construction; For Kakheti - Agriculture (about a third of the region), trade, manufacturing.

In 2018, the largest share of Tbilisi GDP was in real estate activity (19.3\%). Then it would be followed by trade (13.9\%), manufacturing (9.1\%), Financial and insurance activities (8.4\%), Public administration and defence $(6.9 \%)$, construction (6.5\%). For Imereti region the share of activities in the total GDP are as follows: trade (14.5\%), manufacturing (10.6\%), agriculture (8.4\%), construction (7.9\%), public administration (7.8\%), real estate (6.5\%). Adjara Region - Real estate $(22.3 \%)$, trade $(12.9 \%)$, construction (9.5\%); For Kakheti - Agriculture (27.6\%), trade (12.2\%), manufacturing (11.8\%).

The following steps will be taken to improve the regional GDP calculation methods:

$>$ Receiving data directly from local units (local KAUs) by improving information sources;

$>$ More detailing of regionalization. In particular, at the municipal level;

$>$ Calculate regional GDP at constant prices.

Conclusions. Regional structure of GDP of Georgia due from methodological and other changes, in 2018, is as following: Tbilisi - 40.5\%, Imereti - 12.8\%, Adjara - 10.9\%, Kvemo Kartli (9.1\%), Kakheti (6.9\%), Samegrelo-Zemo Svaneti (6.1\%), Shida Kartli (5.5\%), Samtskhe-Javakheti (3.1\%), Mtskheta-Mtianeti (2.3\%), Guria (3.0\%). The smallest share - 0.8\% comes from RachaLechkhumi and Kvemo Svaneti.

Regional GDP on a per capita basis, in 2018 Tbilisi ranks first (6122,5 USD). Then it will be followed by Adjara (5514.3 USD). Their rate is significantly higher than the national rate (4722.0 USD).

These regional data should serve as the basis for regional policy.

\section{REFERENCES}

1. System of National Accounts 2008, European Commission, International Monetary Fund, Organization for economic Co-operation and Development, United Nations, World Bank, New York, 2009, p. 662

2. European System of Accounts, ESA 2010, European Union, 2013, p. 652

3. Manual on regional accounts methods, European Union, 2013, p. 134

4. https://www.geostat.ge/en/modules/categories/23/gross-domestic-product-gdp 